\title{
Benefits and risks of therapeutic alternatives for macrolide resistant Mycoplasma pneumoniae pneu- monia in children
}

\author{
Hyeon-Jong Yang, MD, PhD \\ Pediatric Allergy and Respiratory Center, Department of Pediatrics, Soonchunhyang University Seoul Hospital, Soonchunhyang University College of Medicine, \\ Seoul, Korea
}

Although Mycoplasma pneumoniae pneumonia (MPP) has been generally susceptible to macrolides, the emergence of macrolide-resistant MPP (MRMP) has made its treatment challenging. MRMP rapidly spread after the 2000s, especially in East Asia. MRMP is more common in children and adolescents than in adults, which is likely related to the frequent use of macrolides for treating $M$. pneumoniae infections in children. MRMP is unlikely to be related to clinical, laboratory, or radiological severity, although it likely prolongs the persistence of symptoms and the length of hospital stay. Thereby, it causes an increased burden of the disease and poor quality of life for the patient as well as a societal socioeconomic burden. To date, the only alternative treatments for MRMP are secondary antimicrobials such as tetracyclines (TCs) or fluoroquinolones (FQs) or systemic corticosteroids; however, the former are contraindicated in children because of concerns about potential adverse events (i.e., tooth discoloration or tendinopathy). A few guidelines recommended TCs or FQs as the second-line drug of choice for treating MRMP. However, there have been no evidence-based guidelines. Furthermore, safety issues have not yet been resolved. Therefore, this article aimed to review the benefits and risks of therapeutic alternatives for treating MRMP in children and review the recommendations of international or regional guidelines and specific considerations for their practical application.

Key words: Child, Drug resistance, Fluoroquinolones, Mycoplasma pneumoniae, Tetracycline

\section{Introduction}

Mycoplasma pneumoniae is one of the most common pathogens causing communityacquired pneumonia in school-aged children and young adults. ${ }^{1)}$ The pathogenesis of $M$. pneumoniae infections results from direct epithelial damage or the host's immune response. ${ }^{2,3)}$ The immunological response following infection generates inflammatory reactions that may cause pulmonary and extrapulmonary manifestations. M. pneumoniae attaches to epithelial surfaces in airways and releases toxic molecules (i.e., a pertussis toxin-like protein termed CARDS [community-acquired respiratory distress syndrome] toxin), ${ }^{4)}$ thereby inducing epithelial damage to acquire the nutrients for their growth. ${ }^{5}$

Macrolides are the first-line treatments of M. pneumoniae pneumonia (MPP) mainly because of their low minimum inhibitory concentration (MIC) and because of their safety in young children. Recently, macrolide resistance has been rapidly rising worldwide, particularly in East Asia. Macrolide-resistant MPP (MRMP) first developed in Asia, ${ }^{6}$, where MRMP rates have increased to 90\%-100\% in China, 87\% in Japan, and 84.6\% in Korea. ${ }^{6-8)}$ MRMP has also recently been reported in North America and Europe, as high as 13\% in the United States, 26\% in Italy, and 19\% in Scotland. ${ }^{5,9)}$ The prevalence of MRMP in East Asia contrasts dramatically
Corresponding author: Hyeon-Jong Yang, MD, $\mathrm{PhD}$

Department of Pediatrics, Soonchunhyang University Seoul Hospital, Soonchunhyang University College of Medicine, 59 Daesagwan-ro, Yongsangu, Seoul 04401, Korea

Tel: +82-2-709-9390

Fax: +82-2-709-9083

E-mail: pedyang@schmc.ac.kr https://orcid.org/0000-0002-7287-4300

Received: 20 December, 2018

Revised: 4 March, 2019

Accepted: 13 March, 2019
Copyright (C) 2019 by The Korean Pediatric Society

This is an open-access article distributed under the terms of the Creative Commons Attribution NonCommercial License (http://creativecommons.org/ licenses/by-nc/4.0/) which permits unrestricted noncommercial use, distribution, and reproduction in any medium, provided the original work is properly cited. 
with that in reports from North America or Europe. The high macrolide resistance rates in Asia may be associated with antibiotic selective pressure resulting from extensive macrolide use. ${ }^{10)}$ This is supported by findings from Japan showing that the macrolide resistance rate was highest in areas with extensive macrolide use ${ }^{11)}$ and that it decreased by $43.6 \%$ in 2015 from its highest prevalence of $81.6 \%$ in 2012 along with a reduction in macrolide prescriptions. ${ }^{12)}$

MPP is usually a benign, self-remitting disease. However, it can cause extrapulmonary complications and progress to a severe lifethreatening pneumonia. It has been thought that clinical symptoms, severity of pneumonia, and laboratory and radiographic findings were similar regardless of macrolide resistance. ${ }^{13-15)}$ Generally, acquisition of resistance does not increase the pathogen's virulence but may make treatment more difficult and lead to more complications with ineffective antimicrobial treatment. ${ }^{5)}$ Several studies have indicated that MRMP has been associated with a slower reduction in bacterial load, persistent clinical symptoms such as fever or cough, longer length of hospital stay, and higher rates of pneumonia progression and extrapulmonary complications during macrolide treatment and, thereby, high rates of antibiotic change. ${ }^{16-18)}$ In contrast, macrolides appear clinically effective in some patients infected by macrolide-resistant strains; approximately 30\% of MRMP could be treated by macrolides. ${ }^{13,14,17)}$ This observation can be explained by the fact that MP infections are often self-limited diseases and that the anti-inflammatory effects of macrolides may improve clinical symptoms. Clinical manifestations, such as extrapulmonary complications or radiological deterioration rather than macrolide resistance, are important determinants of the clinical course. ${ }^{7)}$ Therefore, although macrolide resistance might not be a problem in mild cases, therapeutic alternatives might be warranted in severe cases.

Tetracyclines (TCs) and fluoroquinolones (FQs) are recommended as effective alternatives. However, using TCs in children under 8 years of age and FQs in children under 18 years of age are contraindicated by the Korean Food and Drug Administration and blocked by the Korean Drug Utilization Review system because of the potential adverse reactions such as tooth discoloration or tendinopathy. In addition, there are no clinical practice guidelines (CPGs) for treating MRMP in Korean children. Delaying decisions to use alternative antimicrobials may induce further complications of the disease itself, a poor quality of life, as well as a healthcarerelated burden. Therefore, appropriate guidelines supporting clinical decision making need to be developed. This article aims to review the benefits and risks of therapeutic alternatives for treating MRMP in children and to summarize the recommendations of international or regional guidelines and specific considerations for their practical application.

\section{Alternative antimicrobials: guideline recommenda. tions}

Since 2010, 4 CPGs have stated recommendations regarding alternative antimicrobials for treating MPP, ${ }^{1,19-21)}$ and only three CPGs state specific recommendations for treating MRMP. ${ }^{19-21)}$

- The guidelines of the Pediatric Infectious Diseases Society (PIDS) and the Infectious Diseases Society of America (IDSA) for the management of community-acquired pneumonia in infants and children older than 3 months, published in 2011, ${ }^{1)}$ recommend (1) azithromycin as a first-line drug for MPP and (2) doxycycline (for patients aged $>7$ years) or levofloxacin/moxifloxacin (for adolescent patients with skeletal maturity) as second-line oral drugs and erythromycin or levofloxacin as second-line parenteral drugs for MPP. The PIDS and IDSA guidelines do not state specific recommendations for treating MRMP.

- The Guidelines for the Management of Respiratory Infectious Diseases in Children by the Japan Pediatric Society in $2011^{21)}$ and the guiding principles of the Committee of the Japanese Society of Mycoplasmology in $2014^{19)}$ state that (1) macrolides are recommended as the first-line drug of choice for treating MPP, (2) the efficacy of macrolides is assessed by the presence or absence of defervescence within 48-72 hours after initiation of macrolide treatment, and (3) use of tosufloxacin or TCs may be considered for persistent pneumonia that does not respond to macrolides; however, TCs are basically contraindicated in children under 8 years of age.

- The 2015 Hong Kong Practice Recommendation for Management of Community Acquired Pneumonia in Children ${ }^{20)}$ stated that physicians should consider MRMP if children with MPP fail to respond to macrolide therapy and recommended doxycycline for treating MRMP in children $>8$ years of age and when the benefit exceeds the risk for children $\leq 8$ years of age. Levofloxacin is an alternative option to doxycycline for MRMP in children aged $\leq 8$ years. For severe MRMP cases where oral antibiotics cannot be tolerated, intravenous minocycline can be used ( $4 \mathrm{mg} / \mathrm{kg} /$ day on the first day, followed by $2 \mathrm{mg} / \mathrm{kg}$ every 12 hours for a maximum of $100 \mathrm{mg})$.

All of the guidelines' recommendations are not based on evidence but rather based on expert opinion. The first- and second-line antimicrobials and their dose and duration of use are summarized in Table 1.

\section{Benefits and risks of alternative antimicrobials}

The MICs of TCs and FQs against MP are relatively high compared with macrolides, and infection may persist in the airways and disseminate after treatment. ${ }^{22)}$ Therefore, macrolides are the first-line drug of choice for macrolide-sensitive MPP. However, TCs and FQs were shown to be more effective than macrolides in patients infected 
Table 1. Recommended first-line and second-line antimicrobials in the treatment of MRMP in children, optimal doses, and duration of use

\begin{tabular}{|c|c|c|c|c|c|c|}
\hline Country & Line & Drug & $\begin{array}{c}\text { Route of } \\
\text { administration }\end{array}$ & Dose (mg/kg/day) & $\begin{array}{c}\text { Duration of } \\
\text { treatment (day) }\end{array}$ & Notice \\
\hline \multirow[t]{5}{*}{ Japan $^{19,21)}$} & First-line & Erythromycin & Oral & $25-50$ & 14 & \\
\hline & & Clarithromycin & Oral & $10-15$ & 10 & \\
\hline & & Azithromycin & Oral & 10 & 3 & \\
\hline & Second-line & Tosufloxacin & Oral & 12 & $7-14$ & $\leq 8$ years of age \\
\hline & & Minocycline & Oral of IV & $2-4$ & $7-14$ & \\
\hline \multirow[t]{3}{*}{ Hong Kong ${ }^{20)}$} & Second-line & Doxycycline & Oral & 4 & Not mentioned & $>8$ years of age \\
\hline & & Levofloxacin & Oral & 8 & Not mentioned & $\leq 8$ years of age \\
\hline & & Minocycline & IV & 4 & Not mentioned & $\begin{array}{l}\text { When not tolerable oral } \\
\text { medicine }\end{array}$ \\
\hline \multirow[t]{9}{*}{ USA $^{11}$} & First-line & Azithromycin & Oral & $\begin{array}{l}10 \text { on day } 1 \text {, and followed } \\
\text { by } 5 \text { on days } 2-5\end{array}$ & 5 & \\
\hline & & & Oral & 15 & Not mentioned & \\
\hline & & Clarithromycin & Oral & 40 & Not mentioned & \\
\hline & & Erythromycin & IV & 10 on days $1-2$ & Not mentioned & \\
\hline & & Azithromycin & IV & 20 & Not mentioned & \\
\hline & & Erythromycin lactobionate & Oral & 24 & Not mentioned & $>7$ years of age \\
\hline & Second-line & Doxycycline & Oral & 500 mg/day & Not mentioned & Adolescents \\
\hline & & Levofloxacin & IV & $16-20$ & Not mentioned & Adolescents \\
\hline & & Moxifloxacin & Oral & 400 mg/day & Not mentioned & Adolescents \\
\hline
\end{tabular}

MRMP, macrolide-resistant Mycoplasma pneumoniae pneumonia; IV, intravenous.

by MRMP. ${ }^{23)}$ The clinical benefit of TCs and FQs are shortening the duration of symptoms and rapid defervescence. Alternative antimicrobials may be considered when patients remain febrile or chest radiographs shows deterioration at 48-72 hours after macrolide treatment. Although no studies were designed to directly compare the efficacy of TCs and FQs in MRMP, Okada et al. ${ }^{11)}$ reported that minocycline or doxycycline was superior to tosufloxacin regarding improvement of clinical symptoms and reduction in the numbers of DNA copies. Morozumi et al. ${ }^{24)}$ showed that minocycline, doxycycline, and tosufloxacin showed excellent bactericidal activity, but the post-antibiotic effect was lower for tosufloxacin than for minocycline or doxycycline. However, only a few studies compared TCs with tosufloxacin among FQs, and no studies have compared other FQs. Therefore, there is still a limit to compare the effectiveness of TCs and FQs.

TC has been used since 1953, but in the early 1960s, dental side effects were associated with the use of TC. Children with cystic fibrosis who were treated with TC presented a high prevalence $(23 \%-92 \%)$ of tooth discoloration in a dose- and age-dependent manner. ${ }^{25-28)}$

Doxycycline is a second-generation TC with a broad therapeutic spectrum (Rocky Mountain spotted fever [RMSF],$^{29)} \mathrm{Q}$ fever, ${ }^{30)}$ malaria, ${ }^{311}$ and community-acquired pneumonia ${ }^{32}$ ) that rarely causes adverse events. ${ }^{33}$ It has a lower binding affinity to calcium than TC, leading to a reduced risk of tooth discoloration and enamel hypoplasia. ${ }^{34,35}$ Doxycycline treatment at $4 \mathrm{mg} / \mathrm{kg} /$ day for 10 days in children aged 2-7 years with asthma, ${ }^{32)} 2.3 \mathrm{mg} / \mathrm{kg} /$ day for 7 days in children aged 0.2-7.9 years with RMSF, ${ }^{29)}$ and $10 \mathrm{mg} / \mathrm{kg} /$ day for 12.5 days in children $<8$ years of age with CNS infections ${ }^{36)}$ did not induce staining of permanent teeth. There was only one reported case of slightly spotted discoloration of one deciduous tooth after doxycycline use in a prematurely born infants $<2$ months of age. ${ }^{34)}$ Contrary to TC, tooth discoloration was not associated with the duration of doxycycline-use. ${ }^{29)}$ However, discoloration of teeth was observed (2.8\%) in adults receiving prolonged courses of doxycycline (100 mg twice daily for 6 months) for abdominal aortic aneurysms. ${ }^{377}$ Since 2013, the U.S. Centers for Disease Control and Prevention (CDC) have recommended the use of doxycycline at a dose of $2.2 \mathrm{mg} / \mathrm{kg}$ twice daily for 2 weeks in children $<8$ years of age for treating acute and chronic $Q$ fever in the United States. ${ }^{33)}$ The CDC Rickettsial Zoonoses Branch recommends doxycycline for treating tick-borne rickettsial diseases, which continue to cause severe illness and death in otherwise healthy adults and children in the United States in $2016 .{ }^{38)}$ Doxycycline is recommended as a firstline drug when benefits exceed risks.

The FQs are generally well tolerated, but they damage cartilage in the weight-bearing joints of juvenile animals. ${ }^{39)}$ FQ-induced tendinopathy preferentially occurs in adolescents during their pubertal growth spurt following long-term treatment. ${ }^{40)}$ Achilles tendon injuries associated with FQs have been well recognized with an incidence of 0.08\%-2.0\%. ${ }^{41)}$ The U.S. Food and Drug Administration has directed manufacturers of FQs to warn doctors and patients 
about the increased risk of tendinitis and tender rupture as a "black box" warning. ${ }^{42)}$ They have highlighted restricting FQ use to patients with complicated infections and patients for whom there is no suitable alternative antibiotic because of the risk of tendinopathy and other adverse events such as peripheral neuropathy and worsening of myasthenia gravis. ${ }^{43)}$

The Levaquin Pediatric Program, a randomized controlled trial that assessed the efficacy and safety of levofloxacin in children in 1998, reported that the incidence of musculoskeletal disorders (arthralgia, arthritis, gait abnormality, or tendinopathy) was higher in levofloxacin-treated children than in children treated with nonFQ therapy (odds ratio [OR], 2.4; 95\% confidence interval [CI], 1.1-5.2 at 2 months; OR, 1.9; 95\% CI, $1.1-3.5$ at 1 year). ${ }^{44)}$ These disorders were typically transient, and all resolved without apparent sequelae over the 1-year period of observation.

The risk of Achilles tendon rupture seemed to be highest in the first month after exposure. ${ }^{45-47)}$ A systematic review regarding ciprofloxacin safety in pediatric patients (105 studies published between 1950 and 2009, including 16,184 pediatric patients aged $\leq 17$ years) has concluded that the most frequent adverse event of ciprofloxacin was arthropathy; it showed a 57\% increased risk, which appeared reversible with management. ${ }^{48)}$ Tendon rupture is also a well-known complication associated with FQs in adult patients of advanced age, with preceding steroid use, and with underlying diseases, but there are no reports in children to date. ${ }^{49)}$ Taken together, the incidence of FQ-related tendinopathy is negligible, but some of the underlying diseases and concurrent use of corticosteroids may increase the risk or tendinopathy.

\section{Systemic corticosteroids: guideline recommendations}

Patients with MRMP showed higher levels of inflammatory cy- tokines than patients infected with macrolide-sensitive MPP. ${ }^{50,51)}$ These findings suggest that persistent inflammatory stimulation by MRMP may increase the possibility of severe lung lesions and extrapulmonary complications. The pathophysiology of MPP is mainly associated with the host immune reaction. The efficacy of antibiotics for treating MPP was still controversial. ${ }^{52)}$ As an alternative, to reduce inflammation, systemic corticosteroids have been used. Only one guideline stated a specific recommendation for using systemic corticosteroids for treating MRMP in children. The Japanese guideline ${ }^{19)}$ recommended that systemic corticosteroids should be considered for children with serious pneumonia who do not respond to optimal antimicrobial therapy ( $\leq 15$ years of age) and for patients with respiratory failure ( $\geq 16$ years of age) but should not be used in patients who have no clear diagnosis or have not undergone appropriate antimicrobial therapy. Unfortunately, there has been only one randomized controlled trial reporting the effectiveness of corticosteroid add-on therapy. ${ }^{53)}$ There is no study comparing corticosteroids and alternative antimicrobials for treating childhood MRMP. Further studies should be conducted to prove the comparative effectiveness and to establish criteria for systemic corticosteroid treatment and optimal methods of administering corticosteroids. The benefits and risks of therapeutic alternatives are summarized in Table 2.

\section{Specific considerations on the use of therapeutic alternatives}

Intrinsic permanent tooth discoloration may also be resolved by vital bleaching with $\mathrm{H}_{2} \mathrm{O}_{2}$ and composite/porcelain veneers/crowns, and extrinsic tooth discoloration was suggested to be prevented by improving oral hygiene and avoiding sunlight during therapy or taking vitamin C. $^{54,55)}$ Particularly, adverse reactions are more

Table 2. Benefits, risks, and specific consideration of therapeutic alternatives in the treatment of MRMP in children

\begin{tabular}{|c|c|c|c|c|}
\hline Category & Drug & Benefits & Risks & Specific consideration \\
\hline Tetracyclines & $\begin{array}{l}\text { Tetracycline } \\
\text { Doxycycline } \\
\text { Minocycline }\end{array}$ & $\begin{array}{l}\text { Shortening duration of } \\
\text { symptoms and rapid } \\
\text { defervescence }\end{array}$ & $\begin{array}{l}\text { Tooth discoloration ( } 23 \%-92 \%) \\
\text { Tooth discoloration; only } 1 \text { case } \\
\text { under usual dose } \\
\text { Adult-onset tooth }(3 \%-6 \%) \text {, } \\
\text { sclera, skin pigmentation }\end{array}$ & $\begin{array}{l}\text { 1) Safety: Doxycycline > minocycline > tetracycline } \\
\text { 2) short course with appropriate dose may be safe } \\
\text { 3) Improving oral hygiene and avoidance of sunlight-exposure } \\
\text { during therapy } \\
\text { 4) Concerns about resistance for nontargeted microorganisms }\end{array}$ \\
\hline Fluoroquinolones & $\begin{array}{l}\text { Levofloxacin } \\
\text { Tosufloxacin }\end{array}$ & & $\begin{array}{l}\text { Achilles tendinopathy }(0.08 \%- \\
2.0 \%) \\
\text { No available report }\end{array}$ & $\begin{array}{l}\text { 1) Safety: no comparative study among fluoroquinolones } \\
\text { 2) Resistance for urogenital mycoplasma } \\
\text { 3) Specific concern for the development of FQs resistant } M \text {. } \\
\text { Tuberculosis. }\end{array}$ \\
\hline Systemic corticosteroids & & Anti-inflammatory effect & $\begin{array}{l}\text { No available data for safety } \\
\text { No protocol for dose and dura- } \\
\text { tion }\end{array}$ & $\begin{array}{l}\text { 1) The risk of systemic corticosteroids would not exceed the } \\
\text { general, known risk } \\
\text { 2) It cannot reduce bacterial load. Just, it should be consider- } \\
\text { ed for the purpose to reduce intra- or extrapulmonary } \\
\text { inflammations. } \\
\text { 3) Concurrent use with fluoroquinolones may increase a risk } \\
\text { of tendinopathy }\end{array}$ \\
\hline
\end{tabular}

MRMP, macrolide-resistant Mycoplasma pneumoniae pneumonia. 
common with minocycline (3\%-6\% of adult patients), mainly by an extrinsic pathway ${ }^{56)}$ Therefore, a recent systematic review suggested minocycline as alternatives when doxycycline is unavailable. ${ }^{57)}$ TC-induced tooth discoloration may be induced by an intrinsic pathway when used in pregnant women or children $<8$ years of age and also by an extrinsic pathway involving the formation of insoluble TC-calcium orthophosphate complexes that are deposited in dentine and enamel and darken upon exposure to light, even in adults. ${ }^{54,55,58,59)}$ It has been suggested that strict avoidance of sunlight exposure during high-dose, long-term doxycycline therapy can prevent tooth complication. ${ }^{54)}$

FQ-induced tendinopathy is distinguished from other forms of tendinopathy by its abrupt onset and sharp pain that occurs spontaneously. The cardinal sign of tendinopathy is sudden onset and sharp pain that occurs spontaneously on movement or at rest. ${ }^{60)}$ Clinicians should pay attention to joint pain and switch to alternative treatments when joint pain occurs during FQ use, which should be ceased immediately when tendinopathy is suspected. ${ }^{43)}$

In Japan, the incidence of MRMP varies both regionally and epidemically, ranging from $<50 \%$ in patients with no history of macrolide treatment to $>90 \%$ in patients who were treated by macrolides without clinical effectiveness. ${ }^{8}$ Furthermore, the prevalence of MRMP decreased in accord with a decrease in macrolide prescriptions in Japan, ${ }^{12)}$ suggesting that the appropriate use of antimicrobials is essential to control the emerging MRMP.

To date, there is no report on naturally occurring resistance to TCs or FQs against M. pneumoniae. However, resistance to FQs has been reported in urogenital mycoplasmas, ${ }^{61)}$ and in vitro studies have reported resistance for both drugs. ${ }^{62,63}$ In addition, TCs and FQs have a broad antimicrobial spectrum and thereby may promote drug resistance of nontargeted microorganisms. The use of doxycycline for malaria chemoprophylaxis could raise the risk of selecting bacterial pathogens resistant to antibiotics. ${ }^{64)}$ Particularly, the emergence of FQ-resistant Mycobacterium tuberculosis could lead to devastating consequences. Therefore, clinicians should pay attention to the emergence of resistance to these antimicrobials as well as their optimal dose and duration.

\section{Conclusions}

The benefits of therapeutic alternatives obviously outweigh the risks of their adverse outcomes in children with severe MRMP. The initial severity and disease progression rather than only the persistence of fever should be considered in the use of therapeutic alternatives. The role of alternative antimicrobials and systemic corticosteroids is quite different. Systemic corticosteroids should be considered to reduce inflammation in severe intra- or extrapulmonary manifestations. Alternative antimicrobials should be limited to treating MRMP to reduce the bacterial load. Because concurrent use of systemic corticosteroids and FQs might increase the risk of tendinopathy, clinicians should avoid this combination. Taken together, clinicians should consider using therapeutic alternatives when benefits outweigh the risks in MRMP and should be aware of specific considerations for each alternative.

\section{Conflicts of interest}

No potential conflict of interest relevant to this article was reported.

\section{References}

1. Bradley JS, Byington CL, Shah SS, Alverson B, Carter ER, Harrison C, et al. The management of community-acquired pneumonia in infants and children older than 3 months of age: clinical practice guidelines by the Pediatric Infectious Diseases Society and the Infectious Diseases Society of America. Clin Infect Dis 2011;53:e25-76.

2. Waites KB, Talkington DF. Mycoplasma pneumoniae and its role as a human pathogen. Clin Microbiol Rev 2004;17:697-728.

3. Youn YS, Lee KY. Mycoplasma pneumoniae pneumonia in children. Korean J Pediatr 2012;55:42-7.

4. Becker A, Kannan TR, Taylor AB, Pakhomova ON, Zhang Y, Somarajan SR, et al. Structure of CARDS toxin, a unique ADP-ribosylating and vacuolating cytotoxin from Mycoplasma pneumoniae. Proc Natl Acad Sci U S A 2015;112:5165-70.

5. Waites KB, Xiao L, Liu Y, Balish MF, Atkinson TP. Mycoplasma pneumoniae from the Respiratory Tract and Beyond. Clin Microbiol Rev 2017;30:747-809.

6. Hong KB, Choi EH, Lee HJ, Lee SY, Cho EY, Choi JH, et al. Macrolide resistance of Mycoplasma pneumoniae, South Korea, 2000-2011. Emerg Infect Dis 2013;19:1281-4.

7. Yoon IA, Hong KB, Lee HJ, Yun KW, Park JY, Choi YH, et al. Radiologic findings as a determinant and no effect of macrolide resistance on clinical course of Mycoplasma pneumoniae pneumonia. BMC Infect Dis 2017;17:402.

8. Yamazaki T, Kenri T. Epidemiology of Mycoplasma pneumoniae infections in Japan and therapeutic strategies for macrolide-resistant M. pneumoniae. Front Microbiol 2016;7:693.

9. Pereyre S, Goret J, Bébéar C. Mycoplasma pneumoniae: current knowledge on macrolide resistance and treatment. Front Microbiol 2016;7:974.

10. Bébéar C, Pereyre S, Peuchant 0 . Mycoplasma pneumoniae: susceptibility and resistance to antibiotics. Future Microbiol 2011;6:423-31.

11. Okada T, Morozumi M, Tajima T, Hasegawa M, Sakata H, Ohnari S, et al. Rapid effectiveness of minocycline or doxycycline against macrolide-resistant Mycoplasma pneumoniae infection in a 2011 outbreak among Japanese children. Clin Infect Dis 2012;55:1642-9.

12. Tanaka T, Oishi T, Miyata I, Wakabayashi S, Kono M, Ono S, et al. Macrolide-resistant Mycoplasma pneumoniae infection, Japan, 20082015. Emerg Infect Dis 2017;23:1703-6.

13. Matsubara K, Morozumi M, Okada T, Matsushima T, Komiyama O, Shoji M, et al. A comparative clinical study of macrolide-sensitive and macrolide-resistant Mycoplasma pneumoniae infections in pediatric patients. J Infect Chemother 2009;15:380-3.

14. Cardinale F, Chironna M, Chinellato I, Principi N, Esposito S. Clinical 
relevance of Mycoplasma pneumoniae macrolide resistance in children. J Clin Microbiol 2013;51:723-4.

15. Wu PS, Chang LY, Lin HC, Chi H, Hsieh YC, Huang YC, et al. Epidemiology and clinical manifestations of children with macrolideresistant Mycoplasma pneumoniae pneumonia in Taiwan. Pediatr Pulmonol 2013;48:904-11.

16. Kawai Y, Miyashita N, Yamaguchi T, Saitoh A, Kondoh E, Fujimoto H, et al. Clinical efficacy of macrolide antibiotics against genetically determined macrolide-resistant Mycoplasma pneumoniae pneumonia in paediatric patients. Respirology 2012;17:354-62.

17. Suzuki S, Yamazaki T, Narita M, Okazaki N, Suzuki I, Andoh T, et al. Clinical evaluation of macrolide-resistant Mycoplasma pneumoniae. Antimicrob Agents Chemother 2006;50:709-12.

18. Zhou Y, Zhang Y, Sheng Y, Zhang L, Shen Z, Chen Z. More complications occur in macrolide-resistant than in macrolide-sensitive Mycoplasma pneumoniae pneumonia. Antimicrob Agents Chemother 2014;58:1034-8.

19. The Committee of Japanese Society of Mycoplasmology. Guiding principles * for treating for treating Mycoplasma pneumoniae pneumonia [Internet]. Tokyo: Japanese Society of Mycoplasmology; 2014 [cited 2018 Dec 12]. Available from http://square.umin.ac.jp/jsm/ Eng\%20shisin.pdf.

20. Lung DC, Lam DS, Chan E, Chan KC, Chiu SS, Ho PL, et al. Practice recommendations for management of community acquired pneumonia in children. HK J Paediatr 2016;21:178-93.

21. Japan Pediatric Society. The Guidelines for the Management of Respiratory Infectious Diseases in Children. Tokyo: Japan Pediatric Society; 2011 [cited 2018 Dec 5]. Available from https://www.jpeds.or.jp/ uploads/files/saisin_130219_2.pdf.

22. Smith CB, Friedewald WT, Chanock RM. Shedding of Mycoplasma pneumoniae after tetracycline and erythromycin therapy. N Engl J Med 1967;276:1172-5.

23. Kawai Y, Miyashita N, Kubo M, Akaike H, Kato A, Nishizawa Y, et al. Nationwide surveillance of macrolide-resistant Mycoplasma pneumoniae infection in pediatric patients. Antimicrob Agents Chemother 2013;57:4046-9.

24. Morozumi M, Okada T, Tajima T, Ubukata K, Iwata S. Killing kinetics of minocycline, doxycycline and tosufloxacin against macrolideresistant Mycoplasma pneumoniae. Int J Antimicrob Agents 2017; 50:255-7.

25. Shwachman H, Fekete E, Kulczycki LL, Foley GE. The effect of longterm antibiotic therapy in patients with cystic fibrosis of the pancreas. Antibiot Annu 1958-1959;6:692-9.

26. Swallow JN, De Haller J, Young WF. Side-effects to antibiotics in cystic fibrosis: dental changes in relation to antibiotic administration. Arch Dis Child 1967;42:311-8.

27. Rebich T Jr, Kumar J, Brustman B. The St. Regis environmental health issue: assessment of dental defects. J Am Dent Assoc 1983;106:630-3.

28. Boast A, Curtis N, Gwee A. QUESTION 1: Teething issues: can doxycycline be safely used in young children? Arch Dis Child 2016;101: 772-4.

29. Todd SR, Dahlgren FS, Traeger MS, Beltrán-Aguilar ED, Marianos DW, Hamilton C, et al. No visible dental staining in children treated with doxycycline for suspected Rocky Mountain Spotted Fever. J Pediatr 2015;166:1246-51.

30. Anderson A, Bijlmer H, Fournier PE, Graves S, Hartzell J, Kersh GJ, et al. Diagnosis and management of Q fever--United States, 2013: recommendations from CDC and the Q Fever Working Group. MMWR Recomm Rep 2013;62(RR-03):1-30.

31. Gaillard T, Briolant S, Madamet M, Pradines B. The end of a dogma: the safety of doxycycline use in young children for malaria treatment. Malar J 2017;16:148.
32. Volovitz B, Shkap R, Amir J, Calderon S, Varsano I, Nussinovitch M. Absence of tooth staining with doxycycline treatment in young children. Clin Pediatr (Phila) 2007;46:121-6.

33. Smith K, Leyden JJ. Safety of doxycycline and minocycline: a systematic review. Clin Ther 2005;27:1329-42.

34. Forti G, Benincori C. Doxycycline and the teeth. Lancet 1969;1:782.

35. Lambrou DB, Tahos BS, Lambrou KD. In vitro studies of the phenomenon of tetracycline incorporation into enamel. J Dent Res 1977; 56:1527-32.

36. Pöyhönen H, Nurmi M, Peltola V, Alaluusua S, Ruuskanen O, Lähdesmäki T. Dental staining after doxycycline use in children. J Antimicrob Chemother 2017;72:2887-90.

37. Baxter BT, Pearce WH, Waltke EA, Littooy FN, Hallett JW Jr, Kent KC, et al. Prolonged administration of doxycycline in patients with small asymptomatic abdominal aortic aneurysms: report of a prospective (Phase II) multicenter study. J Vasc Surg 2002;36:1-12.

38. Biggs HM, Behravesh CB, Bradley KK, Dahlgren FS, Drexler NA, Dumler JS, et al. Diagnosis and management of tickborne rickettsial diseases: Rocky Mountain spotted fever and other spotted fever group rickettsioses, ehrlichioses, and anaplasmosis - United States. MMWR Recomm Rep 2016;65:1-44.

39. Gough A, Barsoum NJ, Mitchell L, McGuire EJ, de la Iglesia FA. Juvenile canine drug-induced arthropathy: clinicopathological studies on articular lesions caused by oxolinic and pipemidic acids. Toxicol Appl Pharmacol 1979;51:177-87.

40. Pertuiset E, Lenoir G, Jehanne M, Douchain F, Guillot M, Menkès CJ. Joint tolerance of pefloxacin and ofloxacin in children and adolescents with cystic fibrosis. Rev Rhum Mal Osteoartic 1989;56:735-40.

41. Stephenson AL, Wu W, Cortes D, Rochon PA. Tendon injury and fluoroquinolone use: a systematic review. Drug Saf 2013;36:709-21.

42. Tanne JH. FDA adds "black box" warning label to fluoroquinolone antibiotics. BMJ 2008;337:a816.

43. FDA Drug Safety Communication: FDA advises restricting fluoroquinolone antibiotic use for certain uncomplicated infections; warns about disabling side effects that can occur together [Internet]. Silver Spring (MD): U.S. Food \& Drug Administration; 2016 [2018 Dec 12]. Available from: http://www.fda.gov/Drugs/DrugSafety/ucm500143. htm.

44. Noel GJ, Bradley JS, Kauffman RE, Duffy CM, Gerbino PG, Arguedas A, et all. Comparative safety profile of levofloxacin in 2523 children with a focus on four specific musculoskeletal disorders. Pediatr Infect Dis J 2007;26:879-91.

45. Wise BL, Peloquin C, Choi H, Lane NE, Zhang Y. Impact of age, sex, obesity, and steroid use on quinolone-associated tendon disorders. Am J Med 2012;125:1228.e23-1228.e28.

46. van der Linden PD, Sturkenboom MC, Herings RM, Leufkens HM, Rowlands S, Stricker BH. Increased risk of achilles tendon rupture with quinolone antibacterial use, especially in elderly patients taking oral corticosteroids. Arch Intern Med 2003;163:1801-7.

47. van der Linden PD, Sturkenboom MC, Herings RM, Leufkens HG, Stricker BH. Fluoroquinolones and risk of Achilles tendon disorders: case-control study. BMJ 2002;324:1306-7.

48. Adefurin A, Sammons H, Jacqz-Aigrain E, Choonara I. Ciprofloxacin safety in paediatrics: a systematic review. Arch Dis Child 2011;96: 874-80.

49. Jackson MA, Schutze GE; Committee on Infectious Diseases. The use of systemic and topical fluoroquinolones. Pediatrics 2016;138(5). pii:e20162706.

50. Matsuda K, Narita M, Sera N, Maeda E, Yoshitomi H, Ohya H, et al. Gene and cytokine profile analysis of macrolide-resistant Mycoplasma pneumoniae infection in Fukuoka, Japan. BMC Infect Dis 2013; 13:591. 
51. Narita M, Tanaka H. Cytokines involved in the severe manifestations of pulmonary diseases caused by Mycoplasma pneumoniae. Pediatr Pulmonol 2007;42:397.

52. Gardiner SJ, Gavranich JB, Chang AB. Antibiotics for community-acquired lower respiratory tract infections secondary to Mycoplasma pneumoniae in children. Cochrane Database Syst Rev 2015;1: CD004875.

53. Shan LS, Liu X, Kang XY, Wang F, Han XH, Shang YX. Effects of methylprednisolone or immunoglobulin when added to standard treatment with intravenous azithromycin for refractory Mycoplasma pneumoniae pneumonia in children. World J Pediatr 2017;13:321-7.

54. Ayaslioglu E, Erkek E, Oba AA, Cebecioğlu E. Doxycycline-induced staining of permanent adult dentition. Aust Dent J 2005;50:273-5.

55. Good ML, Hussey DL. Minocycline: stain devil? Br J Dermatol 2003; 149:237-9.

56. Mozaffar T, Gordon PH. Minocycline-induced skin and dental pigmentations. Neurology 2006;67:2185.

57. Carris NW, Pardo J, Montero J, Shaeer KM. Minocycline as a substitute for doxycycline in targeted scenarios: a systematic review. Open Forum Infect Dis 2015;2:ofv178.

58. Kashyap AS, Sharma HS. Discolouration of permanent teeth and enamel hypoplasia due to tetracycline. Postgrad Med J 1999;75:772.

59. Nelson R, Parker SR. Doxycycline-induced staining of adult teeth: the first reported case. Arch Dermatol 2006;142:1081-2.

60. Zabraniecki L, Negrier I, Vergne P, Arnaud M, Bonnet C, Bertin P, et al. Fluoroquinolone induced tendinopathy: report of 6 cases. J Rheumatol 1996;23:516-20.

61. Couldwell DL, Tagg KA, Jeoffreys NJ, Gilbert GL. Failure of moxifloxacin treatment in Mycoplasma genitalium infections due to macrolide and fluoroquinolone resistance. Int J STD AIDS 2013;24:822-8.

62. Gruson D, Pereyre S, Renaudin H, Charron A, Bébéar C, Bébéar CM. In vitro development of resistance to six and four fluoroquinolones in Mycoplasma pneumoniae and Mycoplasma hominis, respectively. Antimicrob Agents Chemother 2005;49:1190-3.

63. Dégrange S, Renaudin H, Charron A, Pereyre S, Bébéar C, Bébéar CM. Reduced susceptibility to tetracyclines is associated in vitro with the presence of 16S rRNA mutations in Mycoplasma hominis and Mycoplasma pneumoniae. J Antimicrob Chemother 2008;61:1390-2.

64. Arthur JD, Echeverria P, Shanks GD, Karwacki J, Bodhidatta L, Brown JE. A comparative study of gastrointestinal infections in United States soldiers receiving doxycycline or mefloquine for malaria prophylaxis. Am J Trop Med Hyg 1990;43:608-13. 